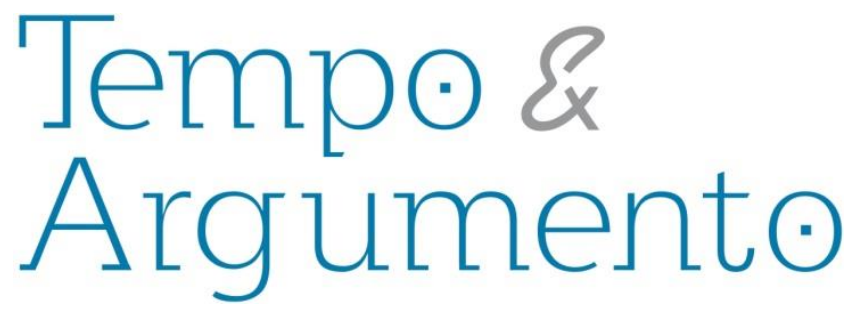

\title{
Entre el pasado y el presente. Entre lo personal y lo político: Narrativas y apuestas de las ex presas políticas en Uruguay
}

\begin{abstract}
Resumen
El pasado reciente en el Cono Sur ha sido rememorado e interpretado desde diversos ejes de memoria. En el Uruguay de los últimos años, han emergido los relatos de las militantes, en dialogo y en disputa a la vez, con el relato hegemónico de los varones y su resistencia heroica. En general estas narrativas se han anclado en las "historias mínimas", la cotidianeidad, el espacio privado (de la cárcel) y en el relato desde "lo femenino", que osciló entre la presentación de un modo de resistencia diferencial reivindicando la agencia de las mujeres, al relato de la peripecia de la cárcel a través de la experiencia de la maternidad en la prisión. Este artículo pretende analizar dos relatos publicados con dos décadas de distancia: Mi habitación, mi celda (1990) de Lilián Celiberti y Lucy Garrido, y Maternidad en prisión política (2010) coordinado por Graciela Jorge, con el objetivo principal de analizar la apuesta política de sus autoras. El primero es el encuentro de dos mujeres con pasados inmediatos y trayectorias políticas distintas, pero embarcadas en un nuevo proyecto político común: el feminismo. El segundo es el encuentro de varias mujeres provenientes de la izquierda armada que inscriben su peripecia en el relato mayor del colectivo de pertenencia. En este sentido el artículo propone reflexionar sobre las distintas funcionalidades que tuvieron los trabajos de la memoria realizados por mujeres, cuánto visibilizaron un nuevo sujeto o cuánto reubicaron a la mujer en su rol tradicional, es decir, en qué medida las narrativas del pasado, permitieron o no dar nuevas batallas a futuro.
\end{abstract}

Palabras clave: Narrativas; Mujeres; Militantes.

\author{
Ana Laura de Giorgi \\ Licenciada y Magister en Ciencia Política por la \\ Universidad de la República del Uruguay. \\ Actualmente se encuentra finalizando su \\ Doctorado en Ciencias Sociales de la \\ Universidad Nacional General Sarmiento \\ (UNGS) y el Instituto de Desarrollo \\ Económico y Social (IDES) en Argentina. \\ Investigadora del Instituto de Ciencia \\ Política de la Universidad de la \\ República del Uruguay, en Régimen de \\ Dedicación Total. Ha obtenido \\ becas de investigación del Consejo \\ Latinoamericano para las Ciencias Sociales \\ (CLACSO) y de la Comisión Sectorial de \\ Investigación Científica (CSIC). \\ Uruguai \\ analauradegiorgi@gmail.com
}

\section{Para citar este artículo:}

DE GIORGI, Ana Laura. Entre el pasado y el presente. Entre lo personal y lo político: Narrativas y apuestas de las ex presas políticas en Uruguay. Tempo e Argumento, Florianópolis, v. 7, n.15, p. 202 - 228. maio/ago. 2015.

\section{DOI: $\mathbf{1 0 . 5 9 6 5 / 2 1 7 5 1 8 0 3 0 7 1 5 2 0 1 5 2 0 2}$}

http://dx.doi.org/10.5965/2175180307152015202 


\section{Between past and present. Between personal and political: Narratives and bets of political ex-prisoners in Uruguay.}

\section{Entre o passado e o presente. Entre o pessoal e o político: Narrativas e apostas das ex-presas políticas no Uruguai.}

\begin{abstract}
The recent past in the Southern Cone has been remembered and interpreted from different memory perspectives. In Uruguay, in recent years, stories written by women have emerged that accompany and at the same time challenge the hegemonic accounts of men and their heroic resistance. In general these narratives are anchored in micro-stories, everyday life, private space (in prison) and stories from the "female perspective". On the one hand this is a form of resistance presented as a result of women's agency. On the other it is an account of events occurring in jail focused on the experience of motherhood in captivity. This article aims to analyze two stories published two decades apart in time: Mi habitación mi celda (1990) and Maternidad en prisión política (2010), with the main objective of analyzing the political challenge faced by the authors. The former book tells of the meeting between two women with different political pasts but involved in a new common political project: feminism. The latter is the meeting between several women from the armed left wing whose experiences are set in the larger story of the group they used to belong to. In this regard, the article's aim is to reflect on the different functions of the memory work undertaken by women, how well they visualize a new subject or how much they relocate women in their traditional role. That is to say, to what extent the narratives of the past contribute to new battles in the future.
\end{abstract}

\begin{abstract}
Resumo
O passado recente no Cone Sul foi rememorado e interpretado desde diferentes aspetos da memória. No Uruguai nos últimos anos, têm surgido as histórias das mulheres militantes políticas, num diálogo e numa disputa com a narrativa hegemônica dos homens e a sua heróica resistência. Em geral, estas narrativas têm-se ancorado nas "histórias de vida," na cotidianidade, no espaço privado (da prisão) e o relato do "feminino", que oscilou entre a apresentação de uma forma de resistência diferencial que reivindicou a agência das mulheres e as vicissitudes da prisão através da experiência da maternidade. Este artigo analisa duas histórias publicadas com vinte anos de distância: Mi habitación, mi celda (1990) e Maternidad en prisión política (2010), com o objetivo de analisar o projeto político de suas autoras. O primeiro narra o encontro de duas mulheres que têm percorrido caminhos recentes e passados políticos distintos, mas que estão engajadas em um novo projeto político comum: o feminismo. O segundo foca-se no encontro de várias mulheres da esquerda armada que inscrevem a suas histórias no coletivo maior ao que pertencem. Neste sentido o artigo reflete sobre as diferentes funcionalidades que teve o trabalho de memória realizado pelas mulheres: quanto visibilizaram um novo sujeito ou quanto colocaram às mulheres no seu papel tradicional, ou seja, em que medida as narrativas do passado geraram oportunidades para iniciar novas batalhas no futuro.
\end{abstract}

Palavras-chave: Narrativas; Mulheres; Militantes.

Keywords: Narratives; Women; Activist. 


\section{Introducción}

A treinta años del retorno democrático en el Uruguay, contamos con una serie de relatos en torno al pasado traumático dictatorial que nos permiten realizar algunas reflexiones en torno a cómo se ha visitado y reconstruido el pasado, y desde que voces se ha realizado este proceso.

Los testimonios orales que circularon tanto en el exterior como en el Uruguay, en el contexto de la transición democrática, otorgaron voz a quienes habían sufrido directamente la violencia dictatorial y sobre todo cumplieron una función denunciatoria del terrorismo de Estado. Los protagonistas de dicha violencia se transformaron en testigos claves respecto a quienes habían desaparecido y así sus experiencias personales quedaron menos visibilizadas. Estas últimas adquirieron un carácter distinto a partir de los procesos de escritura de algunos militantes.

Luego de la liberación de los presos políticos, se editaron algunas memorias que se transformaron claves para el relato de la experiencia carcelaria.. . Estos relatos con un fuerte carácter denunciatorio del terrorismo de Estado, fueron elaborados por los involucrados directamente, que relataron su peripecia carcelaria y permitieron brindar una mirada alternativa al relato oficial de la subversión.

Además de las memorias sobre la experiencia carcelaria, se editaron otro tipo de textos anclados en la etapa previa a la dictadura que reconstruyeron las acciones de las organizaciones políticas, específicamente del Movimiento Nacional de Liberación Tupamaros (MLN-T). En este sentido se publicó Historia de los Tupamaros (1988), La Fuga de Punta Carretas (1990), así como fueron reeditadas las Actas Tupamaras (1987).

Este primer corpus de relato contribuyó entonces al conocimiento de la experiencia carcelaria y su peripecia, a la vez que la hazaña de un movimiento guerrillero que desafió el orden constituido. Aquellos - varones- directamente involucrados

\footnotetext{
* Los primeros textos recogieron correspondencia, reconstruyeron trayectorias y relataron a través del testimonio la peripecia en los centros de detención. Ver Bermejo (1985), Autores varios sobre Wasem (1985), Ronsencof, Fernández (1988), entre otros
} 
así de alguna manera delimitado por una literatura testimonial donde los protagonistas eran aquellos directamente involucrados con el accionar violento que luego sufrirían el encierro y la represión por dichas acciones. El relato se ancló fundamentalmente en acciones épicas y resistencias heroicas a partir de una voz masculina de aquellos que oficiaron a nivel del relato testimonial como "militantes de memoria” (JELIN, 2002, p.62).

Pensar y relatar el pasado desde otras miradas fue un desafío complejo. Sin embargo otros emprendimientos realizados por mujeres y centrados en otros registros, fueron dialogando y contestando con gradaciones distintas el canon testimonial antes referenciado. En 1987 se editó Bitácoras del final. Crónicas de los últimos días de las cárceles políticas, producto de diarios colectivos escritos por las presas de la cárcel de Punta Rieles y en 1990 fue publicado Mi habitación, mi celda, diálogo entre Lucy Garrido y Lilán Celiberti en el que se reconstruye la experiencia carcelaria de esta última. Recién una década después comenzaron a circular los volúmenes de Memorias para armar (2001), De la desmemoria al desolvido (2002) y en 2010 fue publicado Maternidad en prisión política ${ }^{\dagger}$.

Desde esta nueva voz, las mujeres relataron antes que su experiencia militante, la peripecia carcelaria. Sin embargo lo hicieron en términos generales desde un nuevo lugar, que contaba aquellas “historias mínimas”, relatando el mundo de lo privado (de la cárcel) y el relato de una resistencia desde "lo femenino". En estos relatos el lugar para la afectividad será otro elemento de ruptura con aquellas memorias escritas por sus compañeros, y el diálogo será el punto de partida para retornar a un "nosotras" tan común en las memorias de mujeres sobre la cárcel (FORNÉ, 2009).

Como señalan Alejandra Oberti y Roberto Pittaluga (2006:89), algunas memorias de mujeres habilitan además a pensar de un modo distinto los vínculos entre lo público y lo privado, no de forma indiferenciada, pero sí alterando el status jerárquico del primero. En algunos textos, las apuestas en este sentido serán radicales y los relatos desde la

\footnotetext{
${ }^{\dagger}$ A su vez fueron publicados otros textos elaborados por investigadores. Ver Sanseviero y Ruiz (2012); Baica y Risso (Eds.) (2012).
} 
condición de mujer, configurarán "testimonios de concientización” (YÚDICE, 1992). De esta forma, las distintas visitas que se realizan al pasado se constituyen en modos diversos de renegociar la identidad desde nuevas preguntas en el pasado inmediato no estaban disponibles.

Este artículo pretende analizar dos relatos publicados con dos décadas de distancia: Mi habitación, mi celda (1990) y Maternidad en prisión política (2010) ${ }^{\ddagger}$. Las coyunturas en las que se inscriben estos relatos son profundamente distintas y por tanto las formas de rememorar el pasado se ven afectadas. Como se verá a lo largo del texto, paradojalmente un mayor alejamiento de los eventos relatados no implica un mayor nivel de criticidad o lugar para la duda. La sedimentación de algunas memorias puede tornar muy difícil a posteriori la emergencia de fisuras y la visita al pasado se puede volver una operación de reificación. En general la literatura sobre memoria y pasado presenta las distintas producciones testimoniales en un registro de “evolución" hacia mayores niveles de criticidad o surgimiento de memorias alternativas donde la duda, el error, la vergüenza, la disputa se hacen lugar.

Para el caso uruguayo, y específicamente en relación a las memorias de las mujeres, se ha insistido en el viraje que se produjo a partir de la convocatoria para participar en "Memorias para armar" en el año 2000. Diversas autoras (LARROBLA 2012; RUIZ 2013) señalan el necesario paso del tiempo para la emergencia de memorias en un nuevo registro que tomaba distancia del relato hegemónico. Sin embargo, los relatos aquí analizados nos interpelan para repensar esta interpretación ya que aquel de 1989 parece haber sido editado con un espíritu crítico más marcado que aquel de 2010.Las distintas coyunturas dan cuenta de las condiciones de escucha pero también de las condiciones para ejercer la palabra.

El objetivo principal de este artículo es entonces analizar la apuesta política de sus autoras, desde el interés en reflexionar sobre varios aspectos. En primer lugar analizar las disputas y diálogos establecidos en cada una de las propuestas con el relato hegemónico del pasado reciente desplegado por las narraciones masculinas. En segundo, comprender,

\footnotetext{
${ }^{\ddagger}$ Este último texto fue objeto de un primer análisis específico. Ver DE GIORGI, A. L. (2015)
} 
dentro del relato femenino, en qué medida el proceso de memoria es una instancia más de la construcción de los roles de género o la oportunidad para contestarlos. Por último reflexionar sobre las articulaciones y delimitaciones que se establecen entre lo personal y lo político de acuerdo a los marcos interpretativos desde los cuales rememoran las mujeres, definiendo tanto memorias como silencios.

\section{Las mujeres y sus memorias}

Quienes escriben estos testimonios son mujeres directamente afectadas por el terrorismo de Estado. Transitaron por cuarteles y comisarías, sufrieron la tortura física y sicológica, permanecieron aisladas en calabozos por largos períodos y concluyeron su experiencia carcelaria en el Penal de Punta de Rieles, específicamente instalado para las presas políticas de la dictadura. Las protagonistas de estos relatos eran militantes, mujeres y madres que decidieron relatar su experiencia carcelaria desde una perspectiva anclada en la voz de las mujeres y con "otras historias para contar".

Los momentos del testimonio y escritura de estos textos son bien distintos. Por un lado Mi habitación, mi celda, es editado en 1990, - con el reciente fracaso de la derogación de la Ley de Caducidad - , y Maternidad en prisión política en 2010 - con la reemergencia de la agenda de DDHH ante el primer gobierno del Frente Amplio aunque con el segundo intento fracasado por la anulación de la norma antes citadaß̧. La imposibilidad de tramitar los crímenes del terrorismo de Estado ante la justicia claramente restringió la producción de memorias, al menos aquellas que se elaboraron ante juzgados oficiales. Sin embargo los límites también fueron construidos por los primeros relatos testimoniales respecto a los cuales las militantes se encargan de señalar que quedaron excluidas a pesar de sus expectativas. En este sentido, Lucy Garrido se preguntaba en el prólogo:

\footnotetext{
§ En 1989 se realizó en Uruguay un Referéndum para derogar la Ley de Caducidad que impedía juzgar a los responsables del terrorismo de Estado. En 2005 el partido Frente Amplio, coalición de partidos de izquierda, por primera vez en la historia del país asumió el gobierno. En 2009, se sometió a plebiscito la anulación de la Ley de Caducidad y nuevamente la ley quedó vigente.
} 
¿Otra vez la historia sería contada solamente por los hombres, incluso ahora, que en la lucha por la democracia había nacido en el país un movimiento de mujeres exigiendo participación y reivindicando su protagonismo?" (CELIBERTI; GARRIDO, 1990, p.5).

Los prólogos escritos por Celiberti y Garrido dejan entrever un estado de ánimo marcado por el enojo o decepción. Celiberti señalaba que el relato emergía de "la necesidad de reivindicar el derecho a la palabra, nacida del hartazgo de una politiquería que cierra las tenazas del poder sobre nuestros sufrimientos" (1990, p.8). Con menor tono de denuncia el texto Maternidad en... buscará dar cuenta de una "realidad ignorada por la sociedad" (...) de "llenar un hueco en la memoria colectiva haciéndolo con los testimonios de la mayor cantidad posibles de compañeras (2010, p.16). Este es un texto que desde su inicio pretende cumplir con los criterios del canon de la literatura testimonial, es decir, recrear hechos del pasado para darlos a conocer a quienes no lo vivieron.

Los propósitos parecen similares pero no son exactamente los mismos. En un caso se trata de llenar un vacío en la historia y relatar hechos poco conocidos, por ejemplo el de la maternidad en la prisión. En otro se trata no tanto de hechos a dar a conocer sino de voces que habiliten a las mujeres a "hablar de sí mismas", como así lo mencionan las autoras $^{* *}$. En los dos textos la "huella de la oralidad" (ACHUGAR 1992), interpela al lector contando lo "real" y generando un pacto de lectura que como señala Forné (2010) comienza fundamentalmente por su fuente. Los dos textos señalan desde un principio este proceso, cuarenta cassettes grabados productos de horas de conversaciones (CELIBERTI; GARRIDO 1990, p.6) y fragmentos con la menor intervención posible para que lo que realmente "hablara" fueran los testimonios" (JORGE, 2010, p.16).

Los dos textos, y de forma similar a las memorias escritas de los presos políticos, son la construcción de una memoria colectiva, un relato de un proceso que es difícilmente

\footnotetext{
** De todas formas. la "verdad" también pretende ser contada. Celiberti se encarga de relatar al detalle su secuestro en Brasil y la intervención de las fuerzas brasileras. Como señala Jelin (2011, p.556) el Estado juega un rol fundamental en la producción de memorias ya que es en ese ámbito donde se plantearán las demandas de justicia. Aún con la Ley de Caducidad vigente Celiberti no duda en aclarar su detención y exponer el Plan Cóndor.
} 
rememorado en clave individual. Aún en el caso de la peripecia de Celiberti, escuchada y relatada por Garrido, se trata de una memoria escrita a dos voces, en primera y tercera persona que en varios momentos desorienta al lector si este busca individualizar dicha experiencia. Garrido parece ser tan protagonista como Celiberti y la autoría del texto así lo indica. En el caso de Maternidad en... el registro de lo colectivo es aún más fuerte ya que varios testimonios, sólo con iniciales, construyen un relato en conjunto que como se verá más adelante presenta muy pocas fisuras.

Este diálogo es posible porque le da sustento una experiencia compartida: la experiencia como presas en un caso, la experiencia como feministas en otro. Las autorizaciones y comprensiones mutuas son entonces distintas. En Mi habitación...el diálogo se estableció entre feministas y esas son las coordenadas para leerlo, para cuestionar o participar en dicho proceso. Los lugares entonces desde el que se construyen estas memorias son distintos, mientras Celiberti y Garrido nos hablan desde un presente - desde su condición de feministas que rememoran un pasado-, las protagonistas de Maternidad en..., nos hablan de un pasado, el de militantes y presas políticas, sin poder conocer bien los lugares de su presente.

En ningún caso se menciona la procedencia política de quienes relatan. Celiberti y Garrido señalan pertenecer, aún en el momento de edición del libro, a diferentes organizaciones políticas, pero estas no son nominadas. Las protagonistas de Maternidad en..., tampoco señalan directamente las organizaciones políticas en las que militaban al momento de ser detenidas, aunque un lector conocedor de la historia del Movimiento Nacional de Liberación Tupamaros (MLN-T) puede identificar las marcas que nos permiten identificar una filiación político-ideológica. Quienes escriben estos textos son antes que militantes de organizaciones políticas, ex presas, mujeres y madres. 


\section{Mujeres militantes}

Los relatos comienzan desde lugares distintos. Para Lilian Celiberti el relato comienza con la salida de la cárcel, desde donde regresa "pero no del todo", a una casa que está igual pero más vieja y en la que busca el espejo de su madre "para mirarse entera" y saludar a Francesca - su hija- que llegó "arrancada de un cumpleaños". Es un relato breve y acelerado de un momento que quisiera "degustarlo de nuevo". Y después de unas pocas líneas, en donde esa salida movida se carga de múltiples significados que no pueden ni comprenderse, nos chocamos con la detención de Celiberti en Brasil, con las condiciones de la misma - la desnudez y la tortura, el pensamiento sobre los hijos y los hijos desaparecidos de las otras madres detenidas, el de Sara y el de Emilia, a quienes hoy conocemos como Simón y Macarena ${ }^{\dagger}$. En estas primeras dos páginas quedan definidos los marcos para el recuerdo de ese proceso entre la detención y la salida, una peripecia carcelaria marcada por la condición de madre y mujer.

En el caso de Maternidad en... hay un orden cronológico entre un pasado militante muy poco nombrado, el momento de la detención y luego la larga experiencia carcelaria. La etapa previa a la detención es visitada no desde la experiencia concreta sino desde las acciones de la organización política\# así como hitos de la movilización de los sesenta, como la marcha de los cañeros, la visita del Che Guevara al Uruguay en 1961, las ocupaciones estudiantiles y fabriles.

En ninguno de los casos podemos conocer sobre las experiencias militantes. El tiempo de la militancia es presentado sólo como una antesala al tiempo de la cárcel, pero no se visita ni se interroga con nuevas preguntas del presente, como puede apreciarse en otros textos anclados en las experiencias militantes (OBERTI y PITTALUGA, 2006). Sin embargo a pesar de la protección que opera sobre dichos pasados militantes se pueden

\footnotetext{
" Simón, es el hijo de Sara Méndez, ex presa política sobreviviente de la dictadura a quien le secuestraron a su hijo que fue recuperado recién 26 años después. Macarena, hija de los desaparecidos $M^{a}$ Claudia García y Marcelo Gelman, fue recuperada luego de una intensa campaña internacional iniciada por su abuelo, el poeta Juan Gelman en el año 2000. Simón y Macarena son íconos de los hijos secuestrados de presos y desaparecidos en Uruguay.

\# Los pocos textos que abordaban trayectorias de mujeres o acciones donde estas habían participado se inscribían también en el relato de la épica tupamara, como los textos: La leyenda de Yessie Macchi (2000) e Historia de 13 palomas y 38 estrellas: las fugas de la Cárcel de Mujeres (1994) este último editado por Graciela Jorge en 1994, la misma coordinadora del texto aquí en cuestión
} 
identificar algunas marcas que dan cuenta de lo que significó ser joven, mujeres y militante en los sesenta. En “Maternidad en...”, GV, recuerda la primera vez “cuando le tocó subirse a una tribuna, para hablar de la violencia de arriba y la violencia de abajo", RB debió pedir autorización para dormir en el liceo en una ocupación y MEB decidió no casarse por Iglesia lo que le implicó el retiro del respaldo familiar a su casamiento.

La memoria de Celiberti, nos brinda algunas señales sobre el desafío que fue para las mujeres jóvenes encarnar la doble condición de militantes y madres. Ana, amiga de la infancia y compañera de prisión, le había escrito en una carta -antes de ser detenida- que quería "vivir su vida, estudiar y abrirse camino, algo que no había podido concretar hasta el momento de ser detenida. En ambos textos, el tratamiento de "lo personal" y "lo político" en las experiencias militantes de las mujeres dejan algunas huellas por donde podría ser interesante visitar dichos pasados. En cualquier caso, estas referencias son mínimas.

Como señala Daona (2013, p.60), es recurrente que los abordajes sobre las memorias de las mujeres circunscriban la escritura al terreno de lo íntimo y lo doméstico sin detenerse a analizar los roles desempeñados por aquellas en las organizaciones políticas. Probablemente esta ruptura entre pasados militantes y pasados carcelarios, y las formas de relatar la experiencia carcelaria, se deba al menos para el caso uruguayo, en una ausencia de relatos militantes de mujeres y en la reflexión sobre su condición de mujeres militantes. De esta forma lo público y lo privado se articulan de forma distinta de acuerdo a los pasados que se rememoran.

El tiempo de la experiencia y de la agencia de las mujeres se inicia en la otra etapa, unas a través de una resistencia "feminizada", la otra a través de una reflexión de "sí misma" que mira al pasado del pasado de forma crítica. En el relato de la cárcel, es decir en el marco del encierro, la opresión y el terrorismo más brutal, encontraremos a mujeres luchando, es decir con un poder de agencia antes no relatado, por construir otras resistencias e interesadas en uno de los casos en una profunda reflexión sobre la condición de género. 


\section{Presas militantes}

La dictadura implicó unos niveles de violencia física y sicológica brutales que para las mujeres se desplegaron además como violencia de género. Sin embargo este carácter de la violencia y la condición de mujeres sufriéndola es un elemento poco visible. El relato oscila entre la firmeza y la vulnerabilidad, pero esta emerge con cierta legitimidad ante el riesgo que corrían los hijos. En el caso de quienes fueron detenidas estando embarazadas, las militantes se enfrentaron a un doble mandato - no previsto en el manual de interrogatorios ${ }^{\S \S}$, el de cumplir con el mandato militante de "no cantar" y el mandato maternal de proteger al hijo en el vientre. Así LM recordaba preguntarse así misma: “¿cómo me defiendo de esta situación y cómo defiendo la vida de mi hijo? Yo no quería hablar, tampoco quería que mataran a mi hijo" (JORGE, 2010, p.77).

Aún con un discurso más anclado en la experiencia individual y que plantea fisuras de forma recurrente, el relato de Celiberti también se inserta en los marcos de la memoria militante canónica donde recordar "no haber cantado" es un dato ineludible (SEMPOL, 2010). Sólo el lenguaje utilizado da cuenta de las pautas militantes aún compartidas al momento de la escritura, como: "derrota", "vivir con una "actitud indigna" o el “individualismo de las colaboradoras". Una situación que el terror dictatorial impuso, y un lugar sin salida donde las opciones sólo podían ser "preservarse" o "ser una presa política". Celiberti da cuenta de la complejidad de esta situación donde la "cárcel puede ser más destructiva que la tortura" (1990, p.89), sin cuestionarla, como hará con otras temáticas a lo largo de su testimonio.

En el caso de las madres presas, el relato del parto es un momento central para el doble mandato militante y maternal, y para dar pruebas de poder cumplir con ambos. El parto es una experiencia soportada y que culmina de forma exitosa por la fortaleza “natural” - de una madre, a la que se le agrega la voluntad política de atravesar dicha experiencia aportando una dosis de valentía que no poseían sus compañeras de habitación, las esposas de los militares ${ }^{* * *}$. Así lo relataba una de las mujeres presas

\footnotetext{
$\S \S$ El Manual de Interrogatorios del MLN-T indicaba que se debía resistir durante las primeras $24 \mathrm{hs}$ de tortura.

${ }^{* * *}$ Los partos se produjeron en el Hospital Militar, es decir en el mismo lugar donde se atendía el personal
} 
políticas (MC): “Me preocupaba de controlarme, tenía que ser una buena parturienta. Teníamos el rótulo de ser las mejores parturientas del Militar y había que hacerlo”. Esta doble condición de madre y militante se expresaba además en la protección de los niños recién nacidos, cristalización de un proyecto presentado como personal y político, al cual se protegía en ese mismo doble sentido. Así al temor "corriente" de las madres de recibir un hijo que no les perteneciera, se agregaba el riesgo de que el recién nacido, fuera cambiado en el Hospital Militar por el hijo “de algún milico de mierda” (JORGE, 2010, p.99).

\section{Mujeres y madres presas}

Como señala Forné (2009), los relatos de mujeres han hecho mucho énfasis en la solidaridad entre las compañeras y pocas veces surgen fisuras y espacios para la individualidad. El relato construido en el diálogo sobre la vida compartida resulta muy difícil de revisar desde lo individual en la medida que lo colectivo hacía al proyecto político y a las condiciones de reclusión.

Celiberti se mueve de un colectivo a otro, no relata desde una experiencia colectiva entre compañeras políticas, sino entre mujeres, fruto de una estrategia de resistencia específica, que fue relatada en otras memorias a posteriori. Una resistencia feminizada que rompía con otras pautas como el heroísmo, la incapacidad de demostrar sentimientos, de construir espacios mínimos de disfrute. Celiberti, relata cómo las mujeres cantaban, festejaban las alegrías, los cumpleaños con una torta de galletitas, se hacían regalos, ensayaban obras de teatro, se arreglaban el pelo y cosían el uniforme, actividades y actitudes que se afincaban en lo personal y que conducían al "descubrirte mujer" (CELIBERTI; GARRIDO, 1990, p.91) en una apuesta donde resistir la cárcel era el “identificarse con la vida común de cualquier mujer”. En el relato, el colectivo mujeres se fortalece a partir de una mirada que deposita en las mujeres cualidades específicas - en un registro esencialista podríamos señalar- para la amistad, la solidaridad y el 
visibilizar a las mujeres presas y para rememorar desde la condición de mujer es la de madre, aquella que habilitó a las presas a tener una nueva voz desde la que pudieron reclamar en los cuarteles y cárceles ciertas condiciones en relación al cuidado y salud de los niños. El nudo central del relato es el de las madres presas que en pésimas condiciones lograron exitosamente cuidar a sus hijos, cumplieron con el mandato de la maternidad, el cual definió la experiencia carcelaria mientras sus hijos estuvieron a su lado.

La categoría de madre, comenzó a cumplir una función parecida a aquella de mujer abordada en el texto de Ceilberti, es decir a borrar fronteras y establecer lazos casi naturales entre quienes compartían la condición de madres. Uno de los testimonios (CM) lo describe claramente: "Nosotras éramos madres como cualquier otra madre que vivía en cualquier parte del mundo, madres conscientes, madres presas políticas, pero madres" (2010, p.156). La experiencia carcelaria, atravesada por la experiencia de la maternidad, recentraba la resistencia hacia la condición de madres y tomaba distancia de aquella madre-militante que quería ser diferente a las esposas de los militares. "Madres como cualquier otra" implicaba una apelación a la solidaridad de género de otras mujeres. Así el relato destaca especialmente el maltrato recibido hacia ellas por parte de otras mujeres y la condición de mujer de enfermeras y pediatras que no atendieron a sus hijos de la forma adecuada. La acusación política en este caso se dirigía a aquellas mujeres que sirviendo al enemigo desobedecían cierto instinto natural de protección.

Este proceso de recentramiento hacia la maternidad y despolitización de la misma podríamos decir, no debería considerase como una consecuencia natural o personal de quienes tuvieron a sus hijos en la prisión. Las sospechas sobre ellas que esgrimían de forma cotidiana los soldados - que no iban a cuidar bien a sus hijos, que una beba "iba a salir tupita, que los hijos habían sido engendrados en la tatucera y no se sabía quién era el padre - probablemente produjo sus efectos. Las madres presas relatan y se preocupan por dar cuenta al detalle cómo se esforzaron para cumplir con el mandato biológico como cualquier otra mujer en la tierra. Como señala Jelin (2002, p.101), las dictaduras del Cono 
Sur, produjeron mucho más que violencia y terror, sino un discurso conservador con sentencias sobre el “orden "natural” (de género)” que recordaba de forma permanente a las mujeres cuál debía ser su lugar en la sociedad.

La maternidad, objeto de rememoración y reflexión en ambos textos, es la maternidad biológica, no la social como las de quienes oficiaron de madres dentro de la cárcel protegiendo a las que más sufrían, o las abuelas o tías que hicieron de madres una vez que los niños fueron entregados a la familia. La experiencia y el recuerdo está atravesado por esa maternidad, por el "binomio indisoluble madre-hijo", reivindicado por un médico de la propia estructura militar y que las madres presas recuerdan y replican (JORGE, 2010, p.145).

Ese binomio madre-hijo, que excluye otras formas de pensar la crianza - madresabuelas, tías, padres, "padres sociales", constituía una responsabilidad específica para las mujeres, porque eran ellas quienes recibían las acusaciones de malas madres, no sólo de la estructura militar sino de los propios hijos - como le sucedió a Celiberti- y ellas mismas cargaban sobre sí la culpa de no poder cumplir con el rol de madres vigente en la sociedad, como recordaba Celiberti en su memoria: "Es lógico que en el encierro se añoren todas las especies de ternura, lógico querer entrañablemente convivir con los hijos, pero es un peso específico sobre la mujer el considerar que su presencia es insustituible" (CELIBERTI; GARRIDO, 1990, p.63).

La maternidad, no sólo ocupa un rol central en el relato de las que tuvieron sus hijos en prisión, sino también de la memoria de Celiberti. El proceso de reflexión individual en la cárcel y los intentos de tratar ciertas temáticas con las compañeras presas, están directamente vinculados a la maternidad. Celiberti desarma aquellas decisiones "personales" y le otorga un nuevo significado donde su decisión de ser madre es revisada. Lo que había sido considerado como decisión autonómica luego era interpretado como el cumplimiento del destino biológico: "No había hecho más que cumplir con el destino de mujer que la sociedad me había impuesto" (1990, p.52). Aquellas decisiones consideradas "personales" y tomadas con autonomía en una etapa previa, dejaban de serlo, recordando una canción de las feministas italianas que le había enviado a la madre y que en la cárcel se cantaba para ella misma: "siempre creí que había 

pasado inmediato y ver la otra cárcel: "una celda más pequeña que la que en ese momento habitaba", que refiere a la condición de mujer y los mandatos sociales de esta. Cada momento de su vida comenzaba a tener un "hilo único" y algo "se movía en mi interior con ese repasar las cosas" relata Celiberti. El encierro prolongado es castigo, tortura, aislamiento, pero también tiempo para pensar en su experiencia como mujer y la maternidad, ya comprendida como el nudo gordiano de la diferencia sexual, articula esta reflexión. En su celda y su habitación, tal vez de alguna forma en su cuarto propio, aquel espacio necesario demandado por Virginia Woolf, Celiberti se presenta con ansias de discutirlo todo y armar un nuevo proyecto político anclado en la emancipación como mujer hilvanando distintos momentos de la experiencia que terminan siendo interpretados en otro hilo que es el esfuerzo de la autonomía.

De la piedad surgía algo nuevo, algo que había comenzado en Francia, algo que (ahora lo veía más claro) se había afirmado cuando decidí vivir en Brasil, una autonomía y una independencia que me marcarían también un camino duro y conflictivo, pero esta vez elegido por mi (CELIBERTI; GARRIDO, 1990, p.53).

Para quienes tuvieron a sus hijos recién nacidos en prisión, el nudo central del relato no es la reflexión sobre la maternidad y sus mandatos, sino el de la experiencia de la maternidad, vivida, sufrida y disfrutada así como de las funcionalidades de dicha condición en la cárcel. En la etapa de los primeros meses o años de vida de los niños, las presas-madres estuvieron gran parte de su tiempo dedicadas a las tareas cotidianas del cuidado de los hijos dentro de un contexto más que restrictivo y adverso. El desafío era el maternal y cumplir las tareas correspondientes: alimentación, higiene, lavado de ropa, atención de la salud, entretenimiento, que aunque era exigente como no olvidan, se transformaba en un modo de construir un mundo propio, el de la intimidad, los afectos y el vínculo con el hijo, que las alejaba de la violencia y de la locura. Si uno de los problemas de la maternidad para las mujeres, que no se encuentran presas, es la reclusión en el 
Esta experiencia marca entonces el relato del texto coordinado por Jorge (2010), un mundo privado, personal delineado por la experiencia de la maternidad que permitió tomar distancia del relato de la peripecia carcelaria de los presos políticos. Aquella decisión reproductiva política, fruto del amor "entre compañeros" y de un proyecto político en el que se precisaban "niños para amanecer” como consignaba la canción de Daniel Viglietti y como ellas mismas se ocupan de recordar, condujo a las madres presas a una experiencia maternal que las alejaba de lo político, y que tal vez ponía a salvaguarda el mismo proyecto. El proyecto de familia revolucionaria, de algún modo queda salvaguardado en este relato, al ser interrumpido por el terrorismo de Estado, a diferencia de otros casos donde la maternidad de las militantes en el desamparo del compañero y la organización dejaron en evidencia la promesa rota de aquel proyecto (OBERTI, 2010: 28).

Lo personal no es politizado, al menos no la maternidad. Los embarazos son presentados como deseados y buscados. No hay espacio para la duda sobre la maternidad o la posibilidad de renunciar a ella, incluso en un relato que se inscribe en un relato mayo de una organización que habilitó la renuncia a la maternidad en aras de la lucha armada. La pastilla anticonceptiva no es mencionada y mucho menos la práctica del aborto. El momento de emancipación que la militancia había significado para las jóvenes del sesenta, se suspende ante la maternidad, tanto para aquellas que la asumieron en el insilio o el exilio (DE GIORGI 2015), como para quienes la sufrieron y disfrutaron dentro de la cárcel.

Como han señalado varias autoras (FILC, 1997; NARI, 2000), la familia continuó siendo concebida en el relato de los militantes políticos dentro del modelo hegemónico de familia, es decir construida a partir de lazos de sangre que determinan el amor filial con madres que aman "naturalmente" a sus hijos. Si como señala Sempol (2010), el mantenimiento de los patrones de la masculinidad vigente fue una protección para los presos políticos, algo similar parece haber sucedido con las presas políticas, que en el 
caso de las madres contaban con el elemento definitorio de la femineidad de acuerdo a los patrones de la época. En el caso de las madres presas dicha protección no sólo era discursiva y simbólica, sino práctica y cotidiana, sus hijos ocupaban su vida cotidiana y sus preocupaciones.

La experiencia de las madres presas reproduce el discurso familiar y recurre al maternalismo tan característico de los discursos y emprendimientos de memoria desplegados por las mujeres (JELIN, 2010, SHEIBE 2013). Sin embargo cabe preguntarse qué otras posibilidades existían al transformarse la maternidad para las madres presas en una "salida" de la cárcel o la no maternidad una imposición y no una opción para quienes no podían voluntariamente renunciar a ella por estar presas. Los intentos frustrados de discutir algunas cuestiones asociadas a la condición de la mujer que relata Celiberti dan cuenta de lo complejo que resultaba en el contexto de la prisión abrir la caja negra de la trayectoria personal y analizarla críticamente:

Las barreras eran más altas de lo que habíamos pensado, tal vez la cárcel no es el lugar donde puedas abrir de par en par toda tu vida y revisarla, por lo menos en el terreno personal. Resultaba más fácil hacer un análisis político de cuales habían sido tus errores o ideas y remover sobre el proceso histórico que tocar aspectos personales (CELIBERTI; GARRIDO, 1990, p.105).

Lo personal tomaba distancia de lo político y en "mujeres como cualquier otras" y “madres como cualquier otras", las presas encontraban un modo particular de resistencia que se articularía de forma distinta con el relato político mayor. En uno de los textos, la experiencia personal y la reflexión sobre la condición de la mujer es el punto de ruptura y la oportunidad para rediscutir los límites entre lo público y lo privado. En el otro, el tiempo de lo personal y el mundo privado de la maternidad, es un tiempo que interrumpe la narración política y que no encuentra palabras en el terreno de lo político para ser pensado.

Lo personal como terreno de resistencia y lucha, retomó el lugar subordinado que tradicionalmente le ha correspondido en relación a lo público, una vez producida la salida de la cárcel. Para las mujeres particularmente esto implicó el desandar un camino que les había permitido encontrarse en su condición de mujeres. Sin embargo, y como ya había 
sucedido en la etapa previa a la cárcel, las dificultades para pensar lo político y lo personal de forma imbricada permanecían vigentes, como señalaba Celiberti:

Muchas veces escuche decir "los hombres no se complican tanto la vida" y en el fondo de ese comentario había una admiración ancestral hacia el varones y su capacidad de ser más militante y mas simple (...) A la libertad salimos con un patrimonio de gestos, de canciones de fuerza y entusiasmo pero ese equipaje valía poco ante las "reglas de juego" del afuera. (CELIBERTI; GARRIDO, 1990, p.114)

\section{Silencios, olvidos y desmemorias}

El último capítulo de Maternidad en..., da voz a un nuevo sujeto, los hijos de las protagonistas, que comenzaron a conocerse en tanto adultos y a iniciar un proceso de memoria que en ciertas formas contesta el de sus madres. En este apartado las posibilidades para la duda, la discusión, las sensaciones negativas y lo innombrable se hacen cierto lugar. Señalan el lugar que el silencio ocupó en sus vidas, lo que no pudieron hablar, recordar y pensar. Entre los múltiples silencios, llama poderosamente la atención que los hijos sí pueden nombrar lo que no pudo ser dicho por las protagonistas que autorizan el texto: Paloma, la niña concebida y nacida en la prisión.

Maternidad en... narra los hijos concebidos y buscados fuera de la cárcel producto de la pareja militante comprometida, pero no lo que queda por fuera de estas coordenadas, como Paloma, que nació en prisión seis años después de que su madre fuera detenida. En esta maternidad posiblemente se anuda lo que no pudo ser pensado, visitado y relatado: tal vez el amor, sin dudas la sexualidad y una decisión buscada de la maternidad que transgredió los mandatos militantes y también los de género al instrumentalizar la maternidad como herramienta política"t.

En las fotografías al final del texto, Paloma está presente junto a otros jóvenes nacidos en prisión. También están disponibles algunos datos de su nacimiento en un

\footnotetext{
"It El único texto que aborda este asunto es el de SANSEVIERO R. y RUIZ M. (2012) en el que se presenta este caso como producto de una decisión política que permitiría a las mujeres en condición de rehenas ser trasladadas a una cárcel específica para mujeres, como efectivamente sucedió.
} 
cuadro anexo. Sin embargo, sólo un lector conocedor del caso puede reparar en este silencio deliberado sobre una maternidad que escapa al registro general que caracteriza el relato aquí en cuestión. La omisión del caso paradigmático de esta maternidad en prisión, lleva al límite la renegociación del pacto de lectura (Forné 2009) que se reanuda con la voz de los hijos y con los silencios constitutivos de dicho pasado.

El texto escrito por Celiberti y Garrido, aún con muchísimas fisuras que habilitaban la duda, el error, la crítica e interpelaban en más de una oportunidad el relato hegemónico, también registra el mismo silencio. Paloma no es mencionada, pero sí su madre, Jessie, con quien Celiberti compartió la celda en un período que estuvieron "a rigor" y donde desplegaron largas conversaciones sobre cómo "hacer algo para abrir esa temática [la opción de la maternidad] (CELIBERTI; GARRIDO 1990, p.100). Aquí el lector tampoco encuentra elementos para conocer sobre aquella concepción en la prisión y las discusiones - políticas- que implicó.

Jessie y Paloma, apenas mencionadas en cada uno de los textos, aparecen rodeadas de silencio, un silencio que se extiende por dos décadas y sólo es horadado apenas por la voz de los hijos. Los silencios son parte de la memoria Pollak (2006), y hasta se tornan necesarios cuando ciertos hechos no pueden ser parte de algunas modalidades de recordar el pasado. ¿Es que la discusión política de este caso impidió mencionarlo en un registro de la maternidad anclada en lo personal, en una "maternidad pura" como es la relatada en Maternidad en...? ¿Es que hablar desde la maternidad y los niños sólo podía ser posible invisibilizando una maternidad cuestionada y así despolitizándola? La entidad política del caso ¿impidió a otros/as de otros colectivos pronunciarse sobre el mismo, como en Celiberti? El eje divisorio de lo personal y lo político ¿impidió recordar, pensar y/o comprender este suceso?

Este es un claro ejemplo de los silencios negociados (JELIN, 2011.), pero hay otros, que también definieron los límites para pensar la experiencia carcelaria desde la condición de mujer, como aquellos referidos a lo más íntimo de su experiencia durante el terrorismo de Estado: la sexualidad, tanto avasallada, como reprimida. En el primer caso el cuerpo de las mujeres fue un territorio especial para aplicar la violencia en la dictadura. En cada sesión de tortura y en la vida cotidiana de la cárcel les hicieron recordar su doble 
vulnerabilidad, la del enemigo capturado y la de mujer objeto. La violencia se inscribió en el cuerpo de las mujeres y elaborar una memoria respecto a esta experiencia no resultó tarea sencilla, porque la misma intimidad de las mujeres avasalladas por los militares, reproduce vulnerabilidad cuando es puesta en circulación a partir de una memoria que se hace pública. Como señala Jelin (2011, p.564) estos silencios no son olvidos sino decisiones respecto a cómo narrar una experiencia personal y reconstruir el mundo de lo íntimo antes violentado por el terrorismo de Estado.

Luego, tenemos otros silencios, aquellos referidos a la sexualidad administrada y reprimida en el contexto de la experiencia carcelaria, aunque también en un contexto más amplio el de la moral de la época. Las memorias sobre este aspecto son distintas en los textos aquí analizados. En Maternidad en... no hay lugar para el deseo, el amor o el despliegue de la sexualidad. Cualquiera de las categorías desde las que se recuerda, militantes o madres cierran el paso a este tipo de memorias. En Mi habitación... vemos asomarse con pudor algunos temas que en el contexto de la cárcel también se tramitaron por la vía del silencio, como la "profundización de vínculos entre dos compañeras", las fantasías sexuales y la masturbación, o la atracción por un militar.

Hablar y escribir sobre el amor y la sexualidad, han sido temas recurrentemente evitados en las memorias de la cárcel (SEMPOL 2010; MERENSON 2003), porque las condiciones de escucha del afuera, en la etapa inmediatamente posterior a la dictadura pero también treinta años después no han permitido pensar el deseo y el amor cuando estos arriesgaban mandatos militantes o de género. Como señala Graciela Sapriza (2010: 100), muy poco sabemos de aquella supuesta "revolución sexual” de los sesenta y si bien los relatos de mujeres en la cárcel pudieron dar un lugar específico a lo afectivo, a veces presentado como un plus de aquella resistencia femenina, la sexualidad quedó en el repertorio de lo silenciado. 


\section{La prisión femenina}

Al revisar dos textos centrados en la memoria de mujeres presas, uno de los cuales es de los primeros editados y el otro uno de los últimos, podemos comprender las distintas condiciones de escritura, las voces desde las cuales se elaboró la memoria, las distintas imbricaciones de las operaciones de memoria con la experiencia pasada y con el presente desde donde se escribe. Ambos textos se constituyen en una oportunidad para repensar las articulaciones entre experiencia y memoria en los relatos del pasado reciente y en las formas distintas que adquiere la narración de sí mismas por parte de las mujeres.

Lo primero que deberíamos repensar es la categoría “mujer”. Las memorias de las mujeres en general comparten una nueva lectura de pasado y otorgan sentidos distintos a la experiencia carcelaria relatada por los compañeros varones. Sin embargo en modo alguno estas memorias se agotan en el relato de lo cotidiano, lo íntimo y la agencia del cuidado, porque están atravesadas por proyectos políticos que politizan más o menos el espacio de lo personal, y donde esto último adquiere nuevos significados. Las memorias de las mujeres no son memorias "despolitizadas" sino memorias imbricadas en un relato mayor que pueden reproducir un rol subsidiario respecto al mundo de lo ínitmo o impulsar uno que cuestione tal jerarquía.

Claramente son textos que se escriben desde presentes distintos y en este sentido deben recordarse ideas centrales señaladas por autores como Van Alphen (1999) sobre cómo el recuerdo del pasado está interpelado por el presente desde el cual se rememora. En el caso de Celiberti y Garrido, es un texto anclado en una coyuntura de debate y emergencia de un nuevo sujeto político -las mujeres- clave en este relato. Como se menciona en el prólogo, esta memoria viene a contribuir a un espacio público en discusión donde las mujeres ya no pueden permitirse quedar relegadas. En este sentido la categoría mujer se torna central y discute lo que considera medular de esta condición como es la capacidad biológica de ser madres y el mandato moral que condiciona la experiencia, y luego de la lectura, deberíamos decir también la memoria.

En Maternidad en... la coyuntura política es distinta, hay un relato hegemónico sedimentado, tanto en clave masculina como femenina, y hay un momento personal 
específico que es el de la edad de los hijos nacidos en cautiverio, personas adultas capaces de dar cuenta de la exitosa resistencia de sus madres presas. Los hijos, y algunos hijos de los hijos, anudan pasado y presente, conforman el grupo de los niños, y encarnan esa dimensión existencial del pasado relatado. Autorizan la voz de las madres presas, hacen visibles algunos silencios y claramente inhabilitan otras discusiones, como la de la maternidad o la no maternidad. El texto coordinado por Jorge (2010), presenta un relato que disputa con el de las grandes acciones y resistencias heroicas de los compañeros, sin embargo no permite contestar un relato mayor: el de la maternidad como destino natural. La voz es la de las mujeres, pero en tanto madres, que pudieron cumplir con el mandato biológico a pesar del terrorismo de Estado, protegiendo a sus hijos que habían sido buscados a través del amor de la pareja militante. La condición de mujer es casi exclusivamente aquella vinculada a la maternidad, y por tanto, no es suficiente para transgredir en el relato, como nos recuerda Richard (1993, p.137).

En ambos textos poco sabemos de la condición de militantes de las mujeres previo a la cárcel siendo el relato una imagen fija de la experiencia carcelaria que nos dificulta transitar tanto hacia la etapa previa como hacia la salida. En relación al relato hegemónico de los varones militantes, ambos textos se mantienen dentro del relato general de la resistencia a la tortura y el mandato de "no haber cantado" ni ser una "colaboradora".

La maternidad es un nudo central, no sólo de quienes relatan sobre sus hijos en las cárceles sino también de la reflexión que transmite Celiberti. En un caso la cárcel encierra a la maternidad, en otro, la maternidad encierra a las mujeres. Celiberti transmite a lo largo de todo el texto, anclado en la prisión dictatorial, su preocupación por otra prisión la de los mandatos de género y el propio cuerpo. Una cárcel de la cual es mucho más difícil salir y que limita también las formas de visitar el pasado.

El tratamiento de lo personal y lo político es francamente diferente cuando analizamos los textos en cuestión. En Maternindad en... lo privado y lo público continúa reñido en el relato. Lo político da voz a la categoría militante, a los grandes eventos de la organización política de pertenencia, al mantenimiento de los valores militantes y la disciplina. Lo personal otorga voz a las madres, al cuidado de los hijos, a las tareas cotidianas, a los afectos y borra fronteras políticas antes delimitadas. De esta forma lo 
el terreno de lo personal o al menos cuestionar la idea de "naturalidad" de la condición de madre. En este sentido es un relato del pasado pero con claros síntomas de presente, es la narración de no haber podido pensar, hablar y rediscutir un camino que como mujer recibieron como inexorable y la apuesta a dar esa discusión, aunque sea relatando el pasado. Celiberti tal vez es uno de esos testigos que no encuentra nunca la audiencia capaz de escucharla y oírla, como señala Ricoeur (2004:214).

Aún cuando el texto Mi habitación..., se propone discutir algunos componentes centrales del relato hegemónico de los varones militantes y de la sociedad en general respecto a la mujer y la maternidad, como vimos anteriormente, persisten los silencios que dan cuenta de que no todo es discutible o pensable. La búsqueda de politizar lo personal tiene un límite con nombre propio. Una maternidad "política" queda silenciada en ambos relatos y parece no haber categorías disponibles para pensar y relatar tal proceso. Un repertorio de temas y asuntos se despliegan para relatar la maternidad, y otro para la militancia política, el encuentro de ambos mundos no resulta sencillo y los límites para nombrar lo innombrable continúan siendo políticos: Celiberti no se pronuncia sobre quien pertenece a otro colectivo político, quienes escriben en Maternidad en... no se pronuncian sobre quien amenaza los mandatos militantes del colectivo de pertenencia.

Los sentidos que se le otorgan al pasado son entonces distintos. En uno es la recuperación de una experiencia que quedó en el olvido. En otro es el relato de un proceso truncado y que para algunas se encuentra en la agenda de discusión. Los pasados se visitan con expectativas diversas y producen diversos relatos que se articulan de forma distinta con los colectivos de pertenencia al momento de la escritura. Ambos textos denuncian el terrorismo de Estado, y uno de ellos a su vez denuncia el patriarcado. La rememoración de la experiencia en clave personal no siempre implica una reproducción de las relaciones de género (JELIN, 2011, p.566), sino los lugares que ocupa lo personal en el trabajo de memoria de las mujeres. 
En relación a este último aspecto, hay tantas memorias de mujeres como condiciones institucionales, momentos de habla y escucha, expectativas y límites políticos que pueden ser tanto los fijados por los colectivos de pertenencia como los de la sociedad en general. Estas narrativas de mujeres se producen a partir de un repertorio de términos disponibles para cada momento político. Celiberti y Garrido recurren a un discurso que ofreció palabras para nombrar aquello que anteriormente generaba malestar pero no podía ser nominado (OBERTI y PITTALUGA, 2006.89) y que era propio del momento político, articulación que no sucede en un texto que sobreviene veinte años después y que da cuenta de la continuidad de algunos debates obturados.

\section{Bibliografia}

ACHUGAR, Hugo. Historias paralelas / Ejemplares: La historia y la voz del otro. Revista de Crítica Literaria Latinoamericana: año 18, n. 36, p. 51-73, 1992.

CELIBERTI, Lilian; GARRIDO, Lucy. Mi habitación, mi celda. Montevideo: Editorial Arca, 1990.

DAONA, Victoria. Acerca de La Anunciación de María Negroni y la escritura fragmentaria de la violencia política en la Argentina de los años '70. Stockholm Review of Latin American Studies: Issue no. 7, p. 87-98, 2011.

DAONA, Victoria. Mujeres, escritura y terrorismo de estado en Argentina: una serie de relatos testimoniales. Moderna Sprak: p. 56-73, 2013.

DE GIORGI, Ana Laura. La otra nueva ola. Jóvenes mujeres comunistas en el Uruguay de los 60. Revista Izquierdas, №22, p.204.226, 2015

DE GIORGI, Ana Laura. La diferencia en los márgenes. El relato de las madres presas política en Uruguay. Revista TELAR, N 13-14: p.96-113, 2015.

FILC , Judith. Entre el parentesco y la política: Familia y dictadura 1976-1983. Buenos Aires Editorial: Biblos, 1997. 
FORNÉ, Ana. Literatura y testimonio en "Punto estrella". Caminos de lectura. Antología de textos y aproximaciones analíticas al texto literario. Lund Studentlitteratur: p.86-101, 2010.

FORNÉ, Ana. Negociaciones genéricas en los relatos de Memorias para armar. Stockholm Review of Latin American Studies: p. 69-84, 2011.

JELIN, Elizabeth. ¿Víctimas, familiares y ciudadanos/as? Las luchas por la legitimidad de la palabra. In CRENZEL, Emilio (Coord.). Los desaparecidos en la Argentina: Memorias, representaciones e ideas (1983-2008). Buenos Aires: Editorial Biblos, 2010, p. 227-249.

JELIN, Elizabeth. Los trabajos de la memoria. Buenos Aires: Siglo XXI, 2002.

JELIN, Elizabeth. Subjetividad y esfera pública: el género y los sentidos de familia en las memorias de la represión. Política y Sociedad: Vol.48, n.3, p.555-569, 2011.

JORGE, Graciela (Coord.) Maternidad en prisión política: Uruguay 1970-1980. Montevideo: Ediciones Trilce, 2010.

LARROBLA, Carla. El horror femenino. Las representaciones de los episodios traumáticos en testimonios de mujeres víctimas del terrorismo de Estado. In GONZÁLEZ BAICA, Soledad; RISSO, Mariana (Coord.) Las Laurencias: Violencia sexual y de género en el terrorismo de Estado uruguayo. Montevideo: Ediciones Trilce, 2012,

MERENSON, Silvina. Y hasta el silencio en tus labios: Memorias de las ex presas políticas del Penal de Villa Devoto en el transcurso de la última dictadura militar en la Argentina. Tesis, Maestría en Antropología Social, Instituto de Desarrollo Económico y Social (IDES), Instituto de Altos Estudios Sociales (IDAES) de la Universidad Nacional de San Martín (UNSAM), 2003.

OBERTI, Alejandra y PITTALUGA, Roberto. Memorias en montaje. Escrituras sobre la militancia y pensamientos sobre la historia. Buenos Aires: El Cielo por Asalto, 2006.

OBERTI, Alejandra. ¿Qué le hace el género a la memoria?, en Pedro y Scheibe Wolff (Org.). Gênero, Feminismos e Ditaduras no Cone Sul. Florianópolis: Editorial Mulheres, 2010.

POLLAK, Michael. Memoria, Olvido, Silencio: La producción social de identidades frente a situaciones límite. La Plata: Ediciones Al Margen, 2006.

RICOEUR, Paul. La memoria, la historia, el olvido. Buenos Aires: Fondo de Cultura Económica, 2004. 
RUIZ, Marisa. Las prisioneras, a la búsqueda de la memoria perdida en Punta de Rieles. Revista Contemporánea. Año 4, Vol 4, p.79-98, 2013.

RUIZ, Marisa; SANSEVIERO, Rafael. Las rehenas: historia oculta de once presas de la dictadura. Montevideo: Editorial Fin de siglo, 2012.

SAPRIZA, Graciela. Memoria y memorias de mujeres en el relato de la dictadura (Uruguay, 1973-1985), en Pedro y Scheibe Wolff (Org.). Gênero, Feminismos e Ditaduras no Cone Sul. Florianópolis: Editorial Mulheres, 2010.

SEMPOL, Diego. Homosexualidad y cárceles políticas uruguayas. La homofobia como política de resistencia. Sexualidad, Salud y Sociedad, Revista Latinoamericana: $N^{\circ} 4,2010$.

SHEIBE, Cristina. Eu só queria embalar meu filho. Gênero e maternidade no discurso dos movimentos de resistência contra as ditaduras no Cone Sul, América do Sul. Aedos, $N^{\circ} 13$ vol. 5. Ago/Dez. 2013

TALLER DE GÉNERO Y MEMORIA DE EX PRESAS POLÍTICAS. Memorias para armar III: Testimonios coordinados por el Taller de Género y Memoria ex-presas políticas. Montevideo: Editorial Senda, 2003.

TALLER DE GÉNERO Y MEMORIA DE EX PRESAS POLÍTICAS. Memorias para armar II: ¿Quién se portó mal? Testimonios coordinados por el Taller de Género y Memoria expresas políticas. Montevideo: Editorial Senda, 2002.

TALLER DE GÉNERO Y MEMORIA DE EX PRESAS POLÍTICAS. Memorias para armar I: Testimonios coordinados por el Taller de Género y Memoria ex-presas políticas. Montevideo: Editorial Senda, 2001.

TALLER VIVENCIAS DE EX PRESAS POLÍTICAS. De la desmemoria al desolvido: Taller Vivencias de ex-presas políticas, Colección Memorias para armar. Montevideo: Editorial Vivencias, 2004.

VAN ALPHEN, Ernst. Simptoms of Discursivity: Experience, Memory and Trauma. In en BAL M., J. SPITZER. Acts of memory: Cultural recall in the present. Hanover: Dartmouth College, 1999.

YÚDICE, George. Testimonio y concientización. Revista de Crítica Literaria Latinoamericana. Año 18, No. 36, pp. 211-232, 1992. 
